\title{
High-performance control of a three-phase voltage-source converter including feedforward compensation of the estimated load current
}

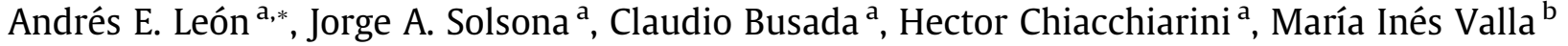 \\ a Instituto de Investigaciones en Ingeniería Eléctrica (IIIE) UNS-CONICET, Universidad Nacional del Sur, Av. Alem 1253, Bahía Blanca 8000, Argentina \\ ${ }^{\mathrm{b}}$ Laboratorio de Electrónica Industrial, Control e Instrumentación (LEICI) and CONICET, Facultad de Ingeniería, Universidad Nacional de La Plata, La Plata 1900, Argentina
}

\section{A R T I C L E I N F O}

\section{Article history:}

Received 28 August 2008

Accepted 6 April 2009

Available online 2 May 2009

\section{Keywords:}

Current estimation

Energy-based control

Feedforward control

AC/DC PWM converter

Voltage regulation

Unity power factor

\begin{abstract}
A B S T R A C T
In this paper a new control strategy for voltage-source converters (VSC) is introduced. The proposed strategy consists of a nonlinear feedback controller based on feedback linearization plus a feedforward compensation of the estimated load current. In our proposal an energy function and the direct-axis current are considered as outputs, in order to avoid the internal dynamics. In this way, a full linearization is obtained via nonlinear transformation and feedback. An estimate of the load current is feedforwarded to improve the performance of the whole system and to diminish the capacitor size. This estimation allows to obtain a more rugged and cheaper implementation. The estimate is calculated by using a nonlinear reduced-order observer. The proposal is validated through different tests. These tests include performance in presence of switching frequency, measurement filters delays, parameters uncertainties and disturbances in the input voltage.
\end{abstract}

(c) 2009 Elsevier Ltd. All rights reserved.

\section{Introduction}

In the last decades, the advance in semiconductor devices allowed the use of power converters in many industrial applications. Voltage-source converters (VSCs) are often used as voltage sources. The main advantages of PWM-VSCs are: unity power factor, sinusoidal input current, high performance of the DC-voltage control, bi-directional power flow, and low total harmonics distortion index. Due to these features VSCs are a good option to be used in industrial drives [1,2], when a source with a highly controlled DC-voltage level is needed. In addition, it must be indicated that the VSC is used in many power applications, since it is an element appearing in more complex topologies (e.g. Active Power Filters, Back-to-Back Converter and Universal Power Quality Conditioner (UPQC) [3-5]). In other applications, such as Flexible AC Transmission Systems (FACTS), VSC is used as a component of different topologies (e.g. Static Synchronous Compensator (STATCOM), Static Synchronous Series Compensator (SSSC), Unified Power Flow Controller (UPFC), and High-Voltage Direct Current (HVDC) [6$8]$ ). Besides, VSCs often appear in a lot of distributed power generation and alternative energy applications [9-15]. Consequently, it is very important to develop control strategies for VSCs satisfying high-performance conditions.

\footnotetext{
* Corresponding author. Tel.: +54 291459 5101x3338; fax: +54 2914595154. E-mail addresses: aleon@ymail.com (A.E. León), jsolsona@uns.edu.ar (J.A. Solsona), mvalla@ing.unlp.edu.ar (M.I. Valla).
}

It must be noted that VSC model is nonlinear, multi-inputmulti-output and under-actuated. In order to control VSCs, several control techniques with different performances can be found in the literature. For example, a strategy based on Jacobian linearization around an equilibrium point has been introduced in [16,17]. However, this strategy presents some drawbacks. Among others, operation range is restricted and a relatively big capacitor is needed for keeping a constant DC-voltage in presence of a varying load. For this reason, nonlinear approaches have been proposed by other researchers. Some of them are based on unstructured controllers (i.e. fuzzy logic and neural networks), although VSC model is highly structured [18]. A back-stepping control was presented in [19], whereas passivity based control can be found in [20]. Also, input-output linearization based on feedback linearization has been applied [21]. This technique transforms the nonlinear system into a linear decoupled one. Then linear control laws can be used for guaranteeing stability in the whole operation range.

It is very important to remark that when DC-voltage is selected as an output, a nonlinear uncontrollable internal dynamics appears (see [22]). In order to overcome this drawback, fast current inner loops, by using feedback linearization taking into account currents as outputs, are generally considered. Then, a slower outer DC-voltage loop is designed via a PI-based cascade control [21-26]. Other options considering simplified models were presented in $[27,28]$. In both papers a model neglecting losses and reactive energy was considered. In [28] the VSC was loaded with a constant resistance and the square of the DC-voltage was taken as a state to be controlled. In this way, the simplified models allow to implement 
a full input-output linearization eliminating the presence of uncontrollable internal dynamics.

VSCs often feed varying loads (either linear or nonlinear). In such cases, feedforward compensator can be designed to improve the controller performance. It is well-known, that feedforward compensation needs more sensors for sensing the variables to be feedforwarded. Many times, designers prefer to avoid extra sensors. In such a case, a common practice consists in replacing the actual sensor by a software sensor (for instance, an observer). By using an observer-based control strategy several advantages appear. The controller is more rugged, more reliable and, also the hardware is less expensive. Moreover, in many applications the current load may contain high frequencies being more convenient to design a mean value estimator, than to obtain a true measurement [29].

In $[26,29]$ software sensors based on open-loop predictors were introduced. In order to improve the performance of open-loop predictors, closed-loop predictors can be designed. Flatness theory has been used to design a nonlinear controller for VSCs loaded with a constant power source and a nonlinear observer has been employed for estimating the unknown load power [30]. The proposed nonlinear observer uses Lyapunov theory to calculate the observer gains. In [24] the load is modeled as a variant resistance and its value is estimated using a full-order observer. However, in order to diminish the computational burden and peaking phenomenon sensibility, a nonlinear reduced-order observer [31] can be built for estimating the load current.

In this paper a new control strategy is introduced. The controller combines a feedback nonlinear law with a feedforward compensation. The feedback law is based on feedback linearization technique where outputs (an energy function and direct-axis current) are chosen in order to avoid the internal dynamics without model simplifications. In this way, a decoupled linear system is attained. For this reason, the proposed technique avoids the drawback appearing in other proposals due to the coupling between the inner current loop and the outer voltage loop.

The feedforward compensation is used for improving the whole system performance. In addition, it must be noted that a smaller capacitor can be used for maintaining the performance obtained with controllers proposed in other works. The load current is estimated via a reduced-order observer. The proposed observer guarantees linear error dynamics so that the convergence of the estimation error is exponential. This is a very important merit of the proposed observer, since the estimates are used in the control loop.

The paper is organized as follows. In Section 2 the VSC model and control strategy design is described. In Section 3, a reduced-order observer for estimating the load current is designed. Performance evaluation, discussion and tests are presented in Section 4. Finally, conclusions are drawn in Section 5.

\section{Control strategy without internal dynamics}

\subsection{Voltage-source converter model}

The VSC model in a rotating reference frame $d q$ is given by [16],

$L \dot{i}_{d}=-R i_{d}-L \omega i_{q}+\eta_{d} v_{d c}-v_{d}$

$L \dot{i}_{q}=-R i_{q}+L \omega i_{d}+\eta_{q} v_{d c}-v_{q}$

$C_{d c} \dot{v}_{d c}=-\frac{3}{2}\left(\eta_{d} i_{d}+\eta_{q} i_{q}\right)+i_{L}$

where $i_{d}, i_{q}, v_{d}$, and $v_{q}$ are the line currents $\left(i_{a}, i_{b}, i_{c}\right)$ and phase voltages $\left(v_{a}, v_{b}, v_{c}\right)$ transformed to the $d q$ reference frame, $\eta_{d}$ and $\eta_{q}$ represent the control signals, $v_{d c}$ is the DC-voltage, and $i_{L}$ is the load current. Parameters can be seen in Fig. 1, where the schematic electric circuit representing the VSC and its load is shown.
Another VSC working in current mode connected to the DC-link is considered as load. Although other loads could be considered (current source, RL impedance, etc.), the proposed kind of load is preferred since it often appears in industrial applications. Moreover, this load is very exigent because it presents high frequency harmonics. For this reason, the challenge in controlling the VSC loaded with another VSC is more interesting to test the proposed control strategy.

\subsection{VSC input-output feedback linearization}

When currents are selected as outputs, the vector relative degree equals to two. However, the model order is three and consequently an internal dynamics appears. As mentioned in the introduction, when the DC-voltage and the direct-axis current are chosen as outputs, simplifications can be proposed for obtaining a control law without internal dynamics. Nevertheless, in order to obtain a control law without neither internal dynamics nor model simplifications, the selection of other outputs must be considered. Our proposal consists of choosing outputs allowing to obtain vector relative degree equal to three. To this end, an energy function $e_{c}$ (relative degree equal to two) is selected as output (see below $\mathbf{h}(\mathbf{x})$ definition). The DC-voltage will be controlled by using this output. In addition, direct-axis current $i_{d}$ (relative degree equal to one) will be controlled to maintain the input unity power factor. By choosing these outputs, the vector relative degree is equal to three. In this way, internal dynamics is avoided. Consequently, complete feedback linearization is obtained and two linear and decoupled loops are to be controlled.

Feedback linearization is applied to the model given by (1)-(3). The system in matrix form becomes,

$\dot{\mathbf{x}}=\mathbf{f}(\mathbf{x})+\mathbf{G}(\mathbf{x}) \mathbf{u}$,

$\mathbf{y}=\mathbf{h}(\mathbf{x})$,

where

$$
\begin{aligned}
& \mathbf{f}=\left[\begin{array}{c}
-\frac{R}{L} i_{d}-\omega i_{q}-\frac{v_{d}}{L} \\
-\frac{R}{L} i_{q}+\omega i_{d}-\frac{v_{q}}{L} \\
\frac{i_{L}}{C_{d c}}
\end{array}\right], \quad \mathbf{G}=\left[\mathbf{g}_{1} \mathbf{g}_{2}\right]=\left[\begin{array}{cc}
\frac{v_{d c}}{L} & 0 \\
0 & \frac{v_{d c}}{L} \\
-\frac{3 i_{d}}{2 C_{d c}} & -\frac{3 i_{q}}{2 C_{d c}}
\end{array}\right], \\
& \mathbf{h}=\left[\begin{array}{l}
h_{1} \\
h_{2}
\end{array}\right]=\left[\begin{array}{l}
e_{c} \\
i_{d}
\end{array}\right]=\left[\begin{array}{c}
\frac{L}{2}\left(i_{d}^{2}+i_{q}^{2}\right)+\frac{C_{d c}}{3} v_{d c}^{2} \\
i_{d}
\end{array}\right], \\
& \mathbf{x}=\left[\begin{array}{lll}
i_{d} & i_{q} & v_{d c}
\end{array}\right]^{T}, \quad \mathbf{u}=\left[\begin{array}{ll}
\eta_{d} & \eta_{q}
\end{array}\right]^{T}, \quad \mathbf{y}=\left[\begin{array}{ll}
e_{c} & i_{d}
\end{array}\right]^{T},
\end{aligned}
$$

where $\mathbf{x}, \mathbf{y}$, and $\mathbf{u}$ are the state, output and input vectors of the nonlinear system, respectively. The control law linearizing the system (4) results (Eq. (6.96) in [32]),

$\left[\begin{array}{ll}\eta_{d} & \eta_{q}\end{array}\right]^{T}=\mathbf{E}^{-1}(\mathbf{x})\left(\left[\begin{array}{ll}u_{e} & u_{d}\end{array}\right]^{T}-\boldsymbol{\alpha}(\mathbf{x})\right)$

where $^{1}$

$$
\mathbf{E} \triangleq\left[\begin{array}{cc}
L_{\mathbf{g}_{1}} L_{\mathbf{f}} h_{1} & L_{\mathbf{g}_{2}} L_{\mathbf{f}} h_{1} \\
L_{\mathbf{g}_{1}} h_{2} & L_{\mathbf{g}_{2}} h_{2}
\end{array}\right], \quad \boldsymbol{\alpha} \triangleq\left[\begin{array}{c}
L_{\mathbf{f}}^{2} h_{1} \\
L_{\mathbf{f}} h_{2}
\end{array}\right] .
$$

By assuming $v_{d}=\dot{v}_{d}=\dot{v}_{q} \cong 0$, for the voltage-source converter model results,

$$
\begin{aligned}
\boldsymbol{\alpha ( \mathbf { x } ) =} & {\left[\frac{2}{3 C_{d c}} i_{L}^{2}+\frac{2 R^{2}}{L}\left(i_{d}^{2}+i_{q}^{2}\right)+\frac{2}{3} \dot{i}_{L} v_{d c}\right.} \\
& \left.+\frac{v_{q}}{L}\left(3 R i_{q}+v_{q}-L \omega i_{d}\right)-\frac{R}{L} i_{d}-\omega i_{q}\right]
\end{aligned}
$$

\footnotetext{
${ }^{1}$ The simplified notation within Lie derivative has been used [32]. Here, $L_{\mathbf{f}}^{n} \lambda$
} denotes the $\lambda$ Lie derivative of $n$ order with respect to $\mathbf{f}$. 
Note that the matrix $\mathbf{E}$ is singular when

$\beta=v_{d c}\left(i_{L} i_{q} L+C_{d c} v_{d c}\left(v_{q}+2 R i_{q}\right)\right)=0$.

A detailed analysis of variables values allows to determine that the function $\beta$ does not become zero in the converter operation range. Notice that $R$ is small and consequently $2 R i_{q}$ can be neglected against $v_{q}$. For this reason, $C_{d c} v_{d c}\left(v_{q}+2 R i_{q}\right)$ is always positive. To our convention $i_{L}$ and $i_{q}$ present the same sign so that $i_{L} i_{q}$ is positive. Consequently, $\beta$ is positive. During transient, when power sign is changing both currents are crossing zero. Therefore, $i_{L} i_{q}$ could have negative sign because currents could have opposite directions. However, in such cases absolute values of the currents are near zero. Then $i_{L} i_{q} L \ll C_{d c} v_{d c} v_{q}$ and consequently $\beta$ is also positive in this case.

By using (6), the system in the transformed domain becomes linear. It is expressed as,

$\ddot{e}_{c}=u_{e}$

$\dot{i}_{d}=u_{d}$.

\subsection{Power factor control}

The power factor is controlled by $i_{d}$. The tracking error is defined as $e_{d}=i_{d}-i_{d}^{\star}$, thus the tracking error dynamics results $\dot{e}_{d}+\gamma_{1} e_{d}+$ $\gamma_{2} \int e_{d} d t=0$, where an integral term has been added to provide robustness against parametric uncertainties. From this equation, and using (10) the auxiliary control value $u_{d}$ is calculated, becoming,

$u_{d}=i_{d}^{\star}-\gamma_{1}\left(i_{d}-i_{d}^{\star}\right)-\gamma_{2} \int\left(i_{d}-i_{d}^{\star}\right) d t$

where the reference value is set to zero $\left(i_{d}^{\star}=0\right)$ for guaranteeing unity power factor. The gains $\gamma_{1}$ and $\gamma_{2}$ can be designed by using linear techniques (poles assignment, linear quadratic regulator, etc.).

\subsection{DC-voltage control}

The voltage $v_{d c}$ in the DC-link will be controlled through the energy function $e_{c}$. By defining the tracking error as $e_{e}=e_{c}-e_{c}^{\star}$, the tracking error dynamics becomes, $\ddot{e}_{e}+\lambda_{1} \dot{\mathrm{e}}_{e}+\lambda_{2} e_{e}=0$. Thus, the auxiliary input $u_{e}$ results,

$u_{e}=\ddot{e}_{c}^{\star}-\lambda_{1}\left(\dot{e}_{c}-\dot{e}_{c}^{\star}\right)-\lambda_{2}\left(e_{c}-e_{c}^{\star}\right)$,

where (9) was used.

From energy definition, power balance, and unity power factor condition the following equalities are obtained,

$e_{c}^{\star}=\frac{L}{2}\left(i_{d}^{\star 2}+i_{q}^{\star 2}\right)+\frac{C_{d c}}{3} v_{d c}^{\star 2}$,

$\dot{e}_{c}^{\star}=p_{c}^{\star}=\frac{2}{3} i_{L} v_{d c}^{\star}-R\left(i_{d}^{\star 2}+i_{q}^{\star 2}\right)-v_{q} i_{q}^{\star}=0$,

$i_{d}^{\star}=0$.

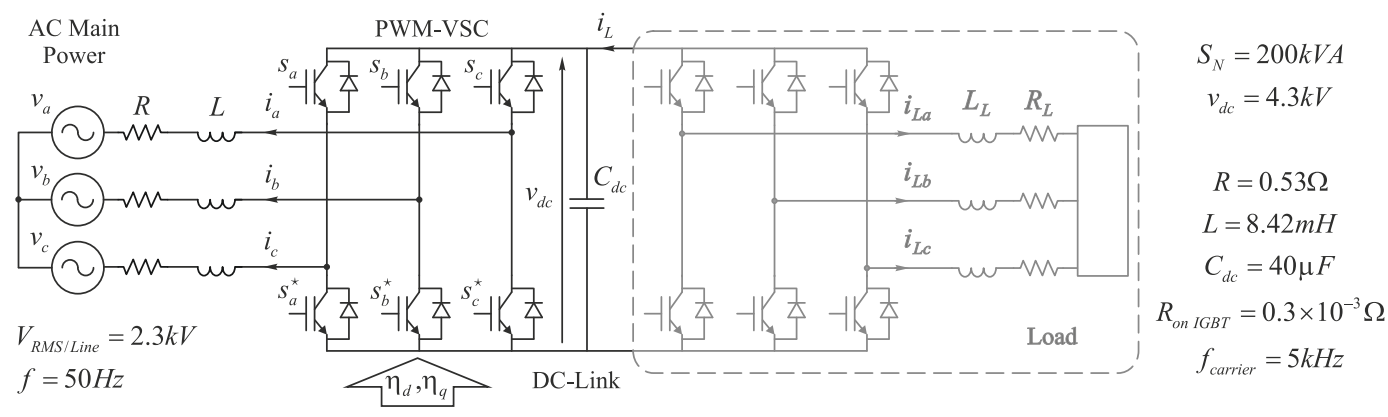

Fig. 1. Electrical circuit of a three-phase voltage-source converter and load.

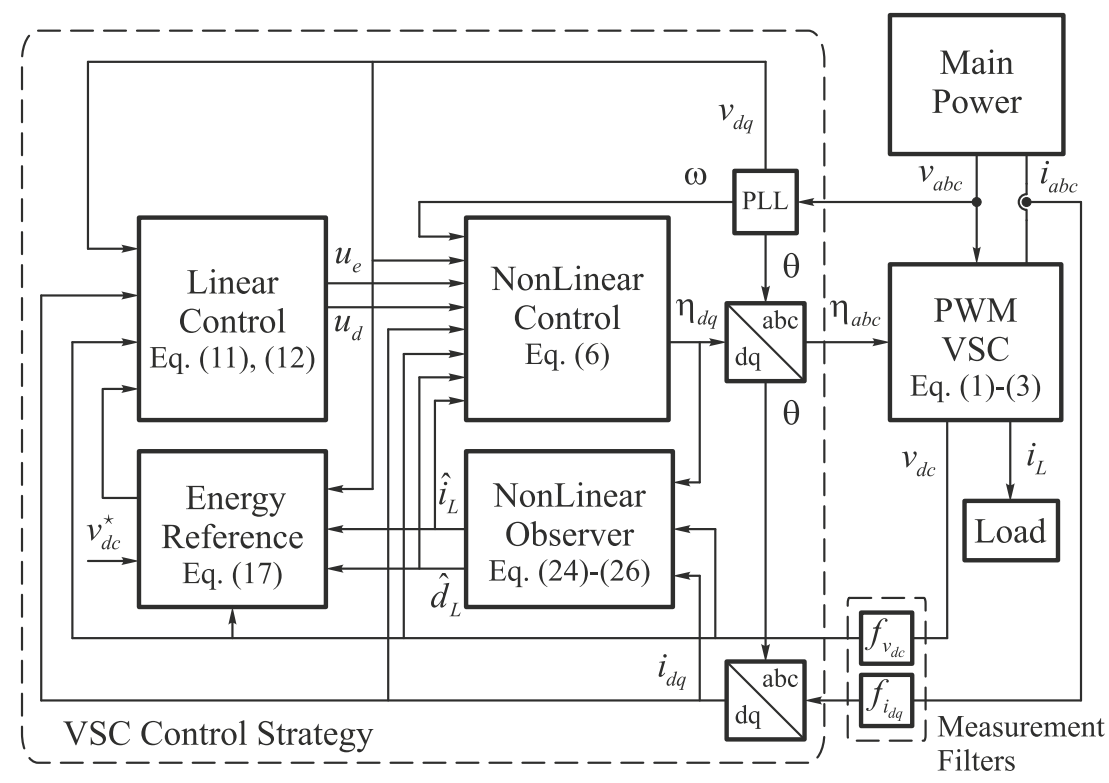

Fig. 2. Block diagram of the proposed control strategy. 
These equations are used for calculating the static energy reference needed to maintain the DC-voltage in a desired value. Then,

$e_{c}^{\star}=\frac{L}{2}\left(\sqrt{\left(\frac{v_{q}}{2 R}\right)^{2}+\frac{2}{3} \frac{i_{L} v_{d c}^{\star}}{R}}-\frac{v_{q}}{2 R}\right)^{2}+\frac{C_{d c}}{3} v_{d c}^{\star 2}$,

where $v_{d c}^{\star}$ stands for the DC-voltage reference, and it is assumed that the load current is known. Note that the energy reference depends on model parameters. For this reason, a dynamical compensation is added to $e_{c}^{\star}$ in order to improve the robustness against model parameters uncertainties. This results in,

$e_{c d y n}^{\star}=e_{c}^{\star}-\rho_{1}\left(v_{d c}-v_{d c}^{\star}\right)-\rho_{2} \int\left(v_{d c}-v_{d c}^{\star}\right) d t$.

Note that the reference given by (17) can be split in two parts. One of them $\left(e_{c}^{\star}\right)$ is used to establish the value of the DC-voltage to be controlled. The other one is small in magnitude, since it is only used for correcting the bias appearing in the energy set-point due to parameters uncertainties. Finally, energy reference given by (17) is used in (12).

\section{Load current estimation}

The feedback linearization needs the load current and its timederivative to be implemented (see $\boldsymbol{\alpha}$ and $\mathbf{E}$ definitions in Eq. (6)). A nonlinear reduced-order observer will be constructed for estimating the load current and its time-derivative. This allows avoiding the use of a current sensor. At the same time it provides a more reliable measure of the current and its derivative, especially when the load current may be discontinuous as is the case of an inverter load.

By arranging the model in a convenient way, it may be rewritten as,

$\dot{\mathbf{x}}=\mathbf{A} \mathbf{x}+\mathbf{B}_{u}(\mathbf{x}, \mathbf{u})+\mathbf{B}_{p} i_{L}$,
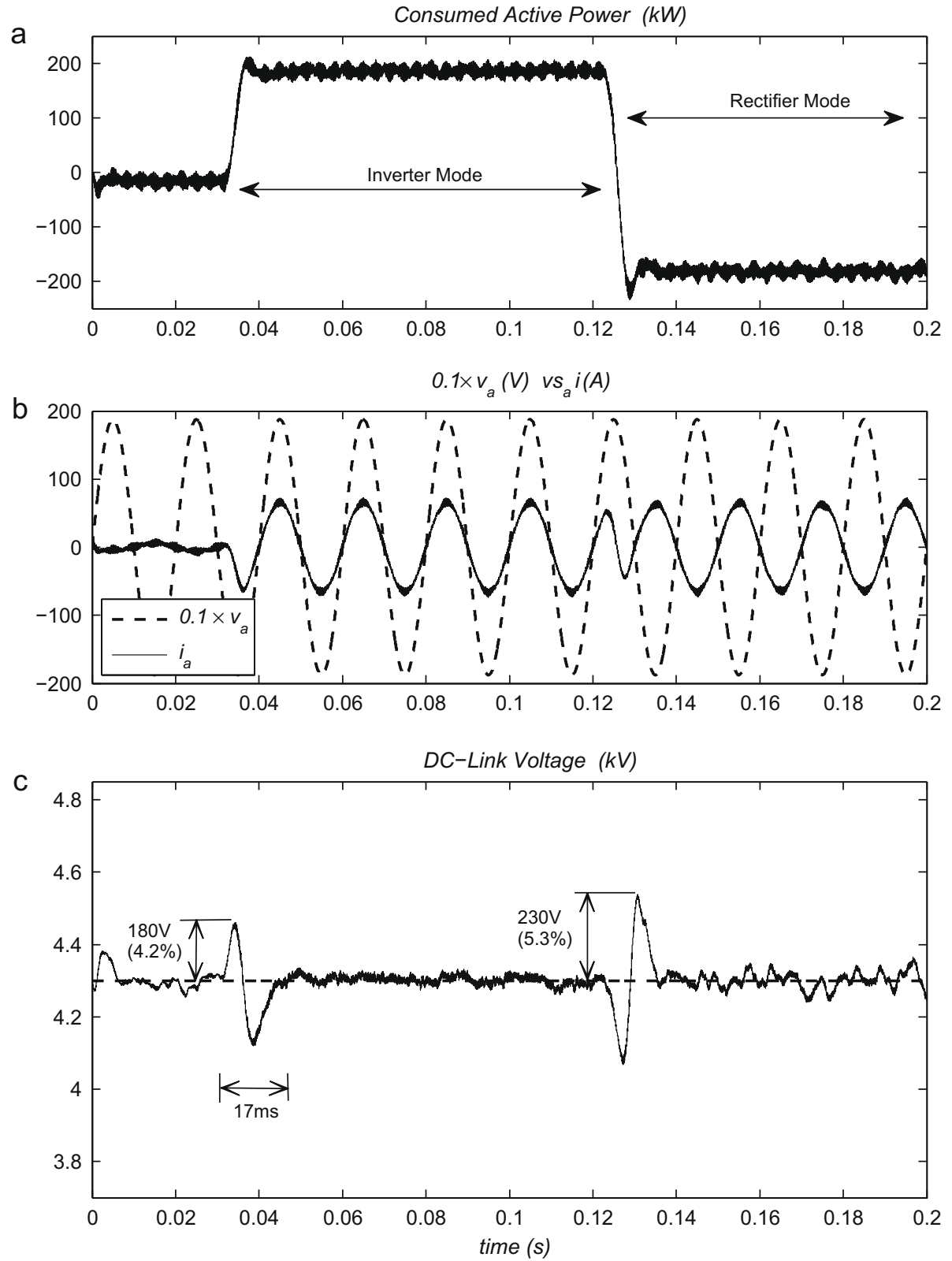

Fig. 3. Active power consumed by the VSC, a-phase current, a-phase voltage and DC-link voltage deviations in presence of disturbances. 
where

$$
\begin{gathered}
\mathbf{A}=\left[\begin{array}{ccc}
-\frac{R}{L} & -\omega & 0 \\
\omega & -\frac{R}{L} & 0 \\
0 & 0 & 0
\end{array}\right], \quad \mathbf{B}_{p}=\left[\begin{array}{c}
0 \\
0 \\
\frac{1}{C_{d c}}
\end{array}\right], \\
\mathbf{B}_{u}(\mathbf{x}, \mathbf{u})=\left[\begin{array}{c}
\frac{\eta_{d} v_{d c}}{L}-\frac{v_{d}}{L} \\
\frac{\eta_{q} v_{d c}}{L}-\frac{v_{q}}{L} \\
-\frac{3}{2 C_{d c}}\left(\eta_{d} i_{d}+\eta_{q} i_{q}\right)
\end{array}\right] .
\end{gathered}
$$

By assuming softly varying load current the system may be extended to,

$$
\left[\begin{array}{c}
\dot{\mathbf{x}} \\
\hline \dot{i}_{L} \\
\dot{d}_{L}
\end{array}\right]=\left[\begin{array}{c|cc}
\mathbf{A} & \mathbf{B}_{p} & \mathbf{0} \\
\hline \mathbf{0} & 0 & 1 \\
\mathbf{0} & 0 & 0
\end{array}\right]\left[\begin{array}{c}
\mathbf{x} \\
\hline i_{L} \\
d_{L}
\end{array}\right]+\left[\begin{array}{c}
\mathbf{B}_{u}(\mathbf{x}, \mathbf{u}) \\
0 \\
0
\end{array}\right],
$$

where $d_{L}$ stands for the load current time-derivative.

For the system represented by (19), a Luenberger nonlinear reduced-order observer is given as shown in [33],

$\dot{\boldsymbol{\xi}}=\mathbf{A}_{r} \boldsymbol{\xi}+\mathbf{B}_{r}+\mathbf{A}_{r} \mathbf{G}_{p} \mathbf{X}$,

$\left[\begin{array}{ll}\hat{i}_{L} & \hat{d}_{L}\end{array}\right]^{T}=\boldsymbol{\xi}+\mathbf{G}_{p} \mathbf{X}$

with,

$$
\begin{aligned}
& \mathbf{A}_{r}=\left[\begin{array}{ll}
0 & 1 \\
0 & 0
\end{array}\right]-\mathbf{G}_{p}\left[\begin{array}{ll}
\mathbf{B}_{p} & \mathbf{0}
\end{array}\right], \\
& \mathbf{B}_{r}=-\mathbf{G}_{p}\left(\mathbf{A}_{r} \mathbf{x}+\mathbf{B}_{u}(\mathbf{x}, \mathbf{u})\right),
\end{aligned}
$$

where $\xi \in \mathbb{R}^{2 \times 1}$ is the observer state vector, and $\mathbf{G}_{p} \in \mathbb{R}^{2 \times 3}$ is the observer gain matrix, designed as a trade-off between measurement noise and estimation error convergence rate. Although the observer structure is nonlinear, the error dynamics of the proposed observer

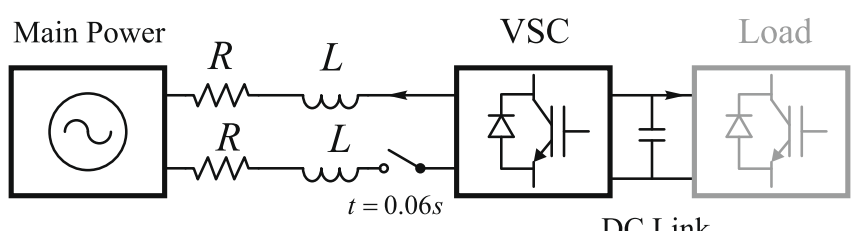

DC Link

Fig. 5. Scheme used for robustness test.

is linear and it is governed by the following expression $\dot{\mathbf{e}}=\mathbf{A}_{r} \mathbf{e}$. Therefore, the gain $\mathbf{G}_{p}$ can be calculated by linear techniques, like pole placement, quadratic optimization techniques, etc. In this way, global exponential speed of convergence is obtained.

By applying this technique to the VSC, the observer obtained via (20) and (21) results,

$$
\begin{aligned}
& \dot{\xi}_{1}=\frac{g_{13}}{C_{d c}}\left(-\xi_{1}-g_{13} v_{d c}+\frac{3}{2}\left(\eta_{d} i_{d}+\eta_{q} i_{q}\right)\right)+\xi_{2}+g_{23} v_{d c}, \\
& \dot{\xi}_{2}=\frac{g_{23}}{C_{d c}}\left(-\xi_{1}-g_{13} v_{d c}+\frac{3}{2}\left(\eta_{d} i_{d}+\eta_{q} i_{q}\right)\right),
\end{aligned}
$$

where the estimated load current and its time-derivative are calculated as,

$\hat{i}_{L}=\xi_{1}+g_{13} v_{d c}$

$\hat{d}_{L}=\xi_{2}+g_{23} v_{d c}$,

where the scalar constants $g_{13}$ and $g_{23}$ are entries of the gain matrix $\mathbf{G}_{p}$. Note that observer expressions given by (24)-(26) are simple enough, such that they can be implemented in commercially available DSPs.

A block diagram illustrating the proposed control strategy with load current estimation is shown in Fig. 2. Note that proposed strategy is a nonlinear law where estimates provided by an observer are included. In the linear case, closed-loop stability (observer-

a

$i_{L}(A)$

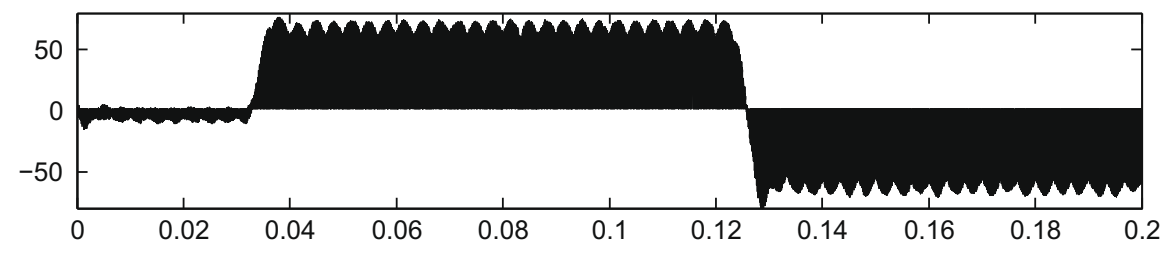

$\hat{i_{L}}(A)$

b

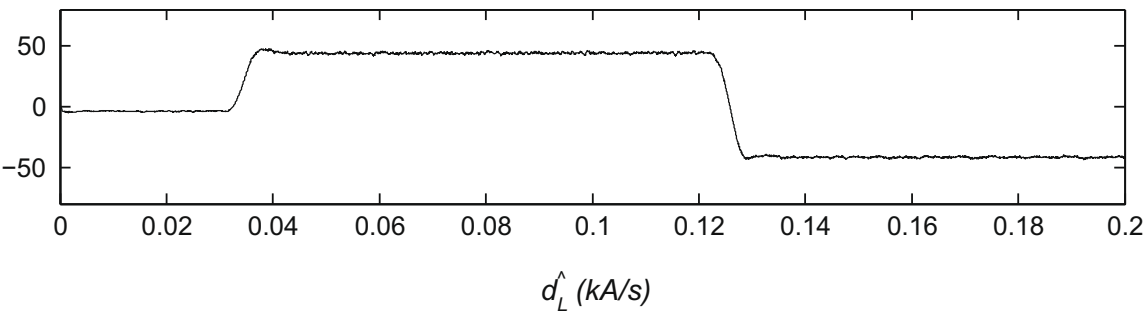

C

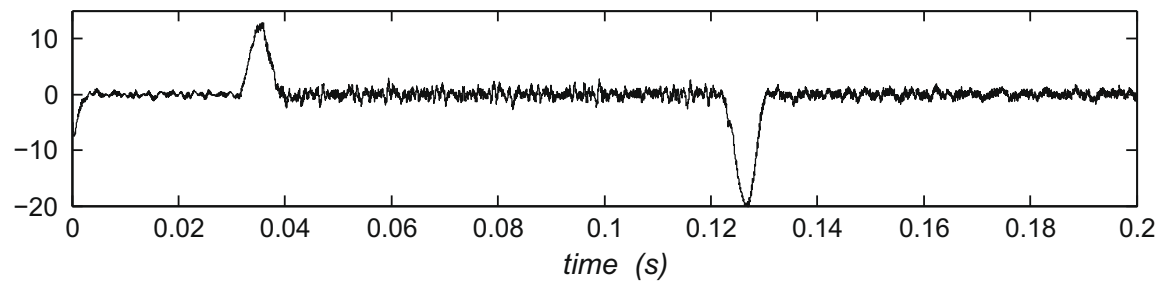

Fig. 4. Actual current and estimated load current and its time-derivative. 
based controller plus plant) is guaranteed by using Separation Theorem [34]. Consequently, the control law and observer convergence speed can be fixed independently. The Separation Theorem does not apply in nonlinear cases. For this reason, in order to choose the observer gains some conditions should be considered to guarantee stability. It is possible to find papers establishing sufficient conditions to guarantee asymptotic convergence in the nonlinear case (see for instance [35-37]). In our case, the observer can be designed proceeding as follows. First, the nonlinear control strategy is calculated by assuming the true states are available. Then, observer gains are selected satisfying the sufficient conditions presented in [38]. These conditions establish how fast must be the observer convergence for guaranteeing closed-loop stability.

\section{Performance testing}

The proposed control was evaluated through several tests, in this Section the most relevant results are presented. The VSC and the controller were implemented in the SimPowerSystems blockset of SIMULINK/MATLAB ${ }^{\mathrm{TM}}$. Controllers gains were set to: $\gamma_{1}=1000 \mathrm{~s}^{-1}, \quad \gamma_{2}=1 \times 10^{5} \mathrm{~s}^{-2}, \quad \lambda_{1}=1500 \mathrm{~s}^{-1}, \quad \lambda_{2}=3.6 \times 10^{5} \mathrm{~s}^{-2}$, $\rho_{1}=0.05 \mathrm{~J} \mathrm{~V}^{-1}$, and $\rho_{2}=10 \mathrm{~J} \mathrm{~V}^{-1} \mathrm{~s}^{-1}$, whereas observer gains were $g_{13}=0.2 \mathrm{~A} \mathrm{~V}^{-1}$, and $g_{23}=255 \mathrm{~A} \mathrm{~V}^{-1} \mathrm{~s}^{-1}$. Other data and parameters are shown in the electrical circuit presented in Fig. 1. To obtain a digital controller, the Euler rule was employed for discretizing continuous equations $\dot{x} \cong \frac{x_{k+1}-x_{k}}{h}$, where $h$ is the sample time, and it was set to $100 \mu$ s.

\subsection{Dynamic behavior in presence of load changes}

In a first test, the load current was varied from zero to nominal value. Then, the power flow direction was suddenly changed for showing the regenerative behavior and the transient response of the proposed controller. In Fig. 3a the consumed active power is illustrated. VSC a-phase current and voltage trajectories are presented in Fig. 3b. It can be seen that both trajectories are in-phase (or contra-phase) every time (unity power factor condition). It is still verified during transients and in presence of sudden changes of active power consumed by the load. This behavior is achieved by using the proposed controller, since the current loop controlling $i_{d}$ (reactive power) is decoupled. Fig. 3c shows the DC-voltage regulation, where only small deviations are observed. These deviations are smaller than 5.3\%, and they last less than $17 \mathrm{~ms}$. This is because the proposed strategy contains nonlinear model information and a feedforward compensation for rejecting the disturbance.

a
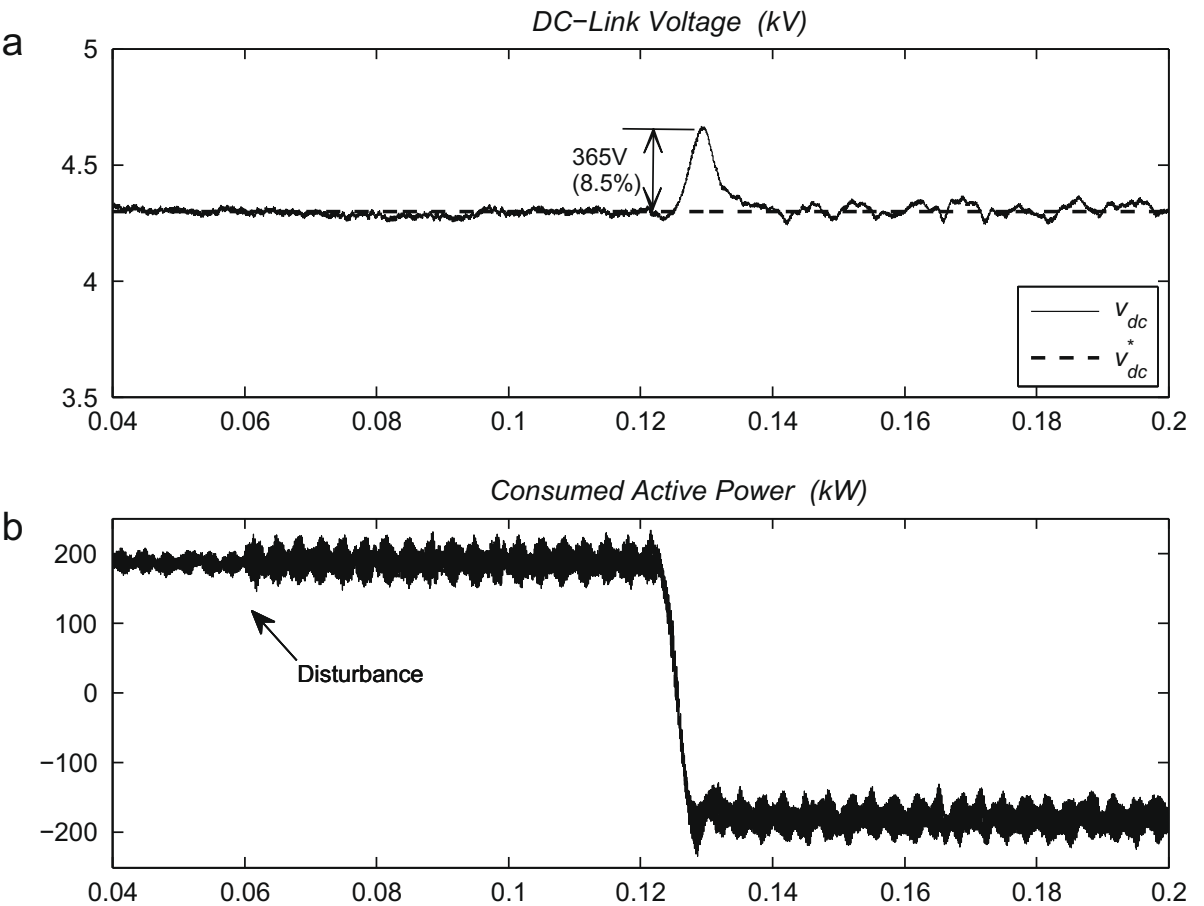

C

Consumed Reactive Power (kVAr)

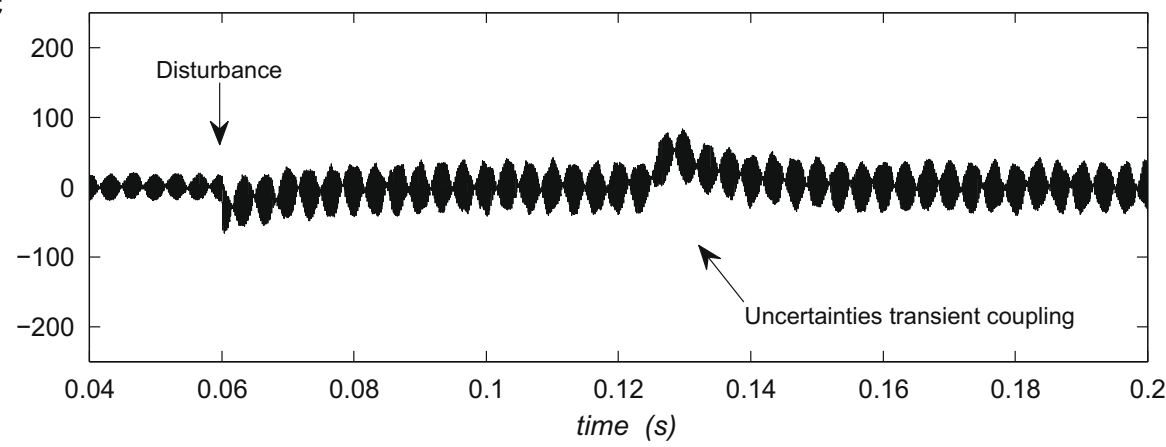

Fig. 6. Parameters uncertainties test. 
Due to its predictive action, feedforward compensation allows to reject the disturbance in a fast way. Note that traditional DC-voltage controllers based on PI acts when the error introduced by the disturbance is detected.

The observer performance is presented in Fig. 4. It must be noted that the load current presents high harmonics (see Fig. 4a. This issue must be taken into account when a load current feedforward compensation is to be implemented. In this case, an estimator of the load current mean value is more effective than a direct measurement, since the high harmonics of the load current are not feedforwarded. Fig. $4 \mathrm{~b}$ and $\mathrm{c}$ shows the estimated load current and its estimated time-derivative. These estimates are injected as feedforward terms in the control law for avoiding current sensors.

\subsection{Robustness against parameters uncertainties}

In order to analyze the robustness of the proposed controller against parameters uncertainties, another line with the same resistance $(R)$ and the same inductance $(L)$ is connected in parallel configuration (see Fig. 5). When this line is connected (at $t=0.06 \mathrm{~s}$ ) the impedance is reduced to $50 \%$. Then, while this condition is maintained the load power flow direction is changed from the positive nominal value to negative nominal value. In Fig. 6a it can be seen that the proposed strategy allows to reject this disturbance in a good way. Fig. 6b and c shows the active power trajectory and the consumed reactive power. Note that an error appears when the line is connected at $t=0.06 \mathrm{~s}$, but the reactive power value is recovered in a short period of time. It is interesting to remark that at $t=0.13 \mathrm{~s}$ a deviation in the reactive power curve occurs. This deviation takes place due to mismatches between the controller and the actual line parameters (in this case, the impedance was reduced to 50\%) which avoids the perfect transient decoupling. However, this error is small and it can be asserted that the proposed strategy performs well, taking into account the severe test conditions.

\subsection{Voltage sag test}

In this subsection a voltage sag test is carried out. The input voltage is reduced to $50 \%$ of the nominal value during $100 \mathrm{~ms}$. Fig. 7a illustrates the dynamic response of the DC-link voltage. It remains well regulated except for short transients when the input voltage changes abruptly. In Fig. 7b the a-phase voltage and current evolutions during the sag are shown. The proposed controller maintains current and voltage in-phase attaining unit power factor at every time.

\subsection{Behavior under unbalanced conditions}

The behavior of the proposed strategy under an asymmetric fault in the electrical network is analyzed. An unbalance equal to $15 \%$ in the AC voltage is considered. Fig. 8a shows the converter input voltages where the unbalance is clearly seen. The DC-voltage is shown in Fig. 8b. It is regulated to a constant value, but a ripple appears when the voltage is unbalanced. This is due to the assumption that $v_{d}=\dot{v}_{d}=\dot{v}_{q} \cong 0$, which is not exactly satisfied when the system presents some unbalance. However, the ripple magnitude is less than $2 \%$ at $2 \omega$ frequency due to a negative sequence existing in the AC voltage. Nevertheless the control strategy can be improved considering that these terms have a finite value, but this is not justified to correct such a small ripple. Note that voltage and current are in-phase at every time, as shown in Fig. 8c. It can be inferred that although the input voltage is unbalanced, unity power factor is kept.

\subsection{Voltage tracking}

The last test was constructed for analyzing the controller performance under voltage tracking situation. In some applications, the DC-voltage must be varied for adjusting it to a given value. In order to test this situation, the DC-voltage reference is varied from $4.3 \mathrm{kV}$ to $5 \mathrm{kV}$, while the load demands the nominal power. Fig. 9
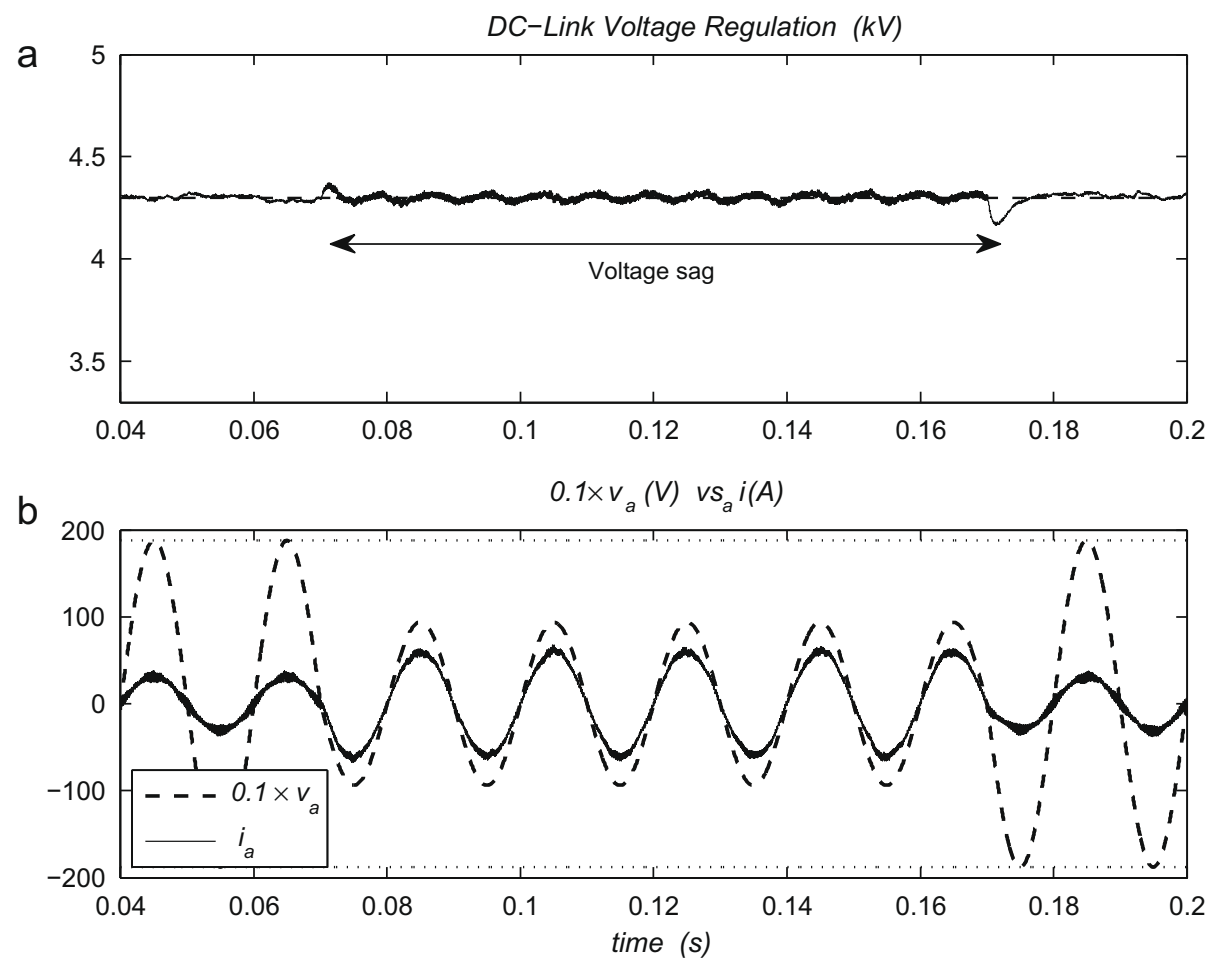

Fig. 7. Voltage sag test. 
a

Input Voltage $(\mathrm{kV})$
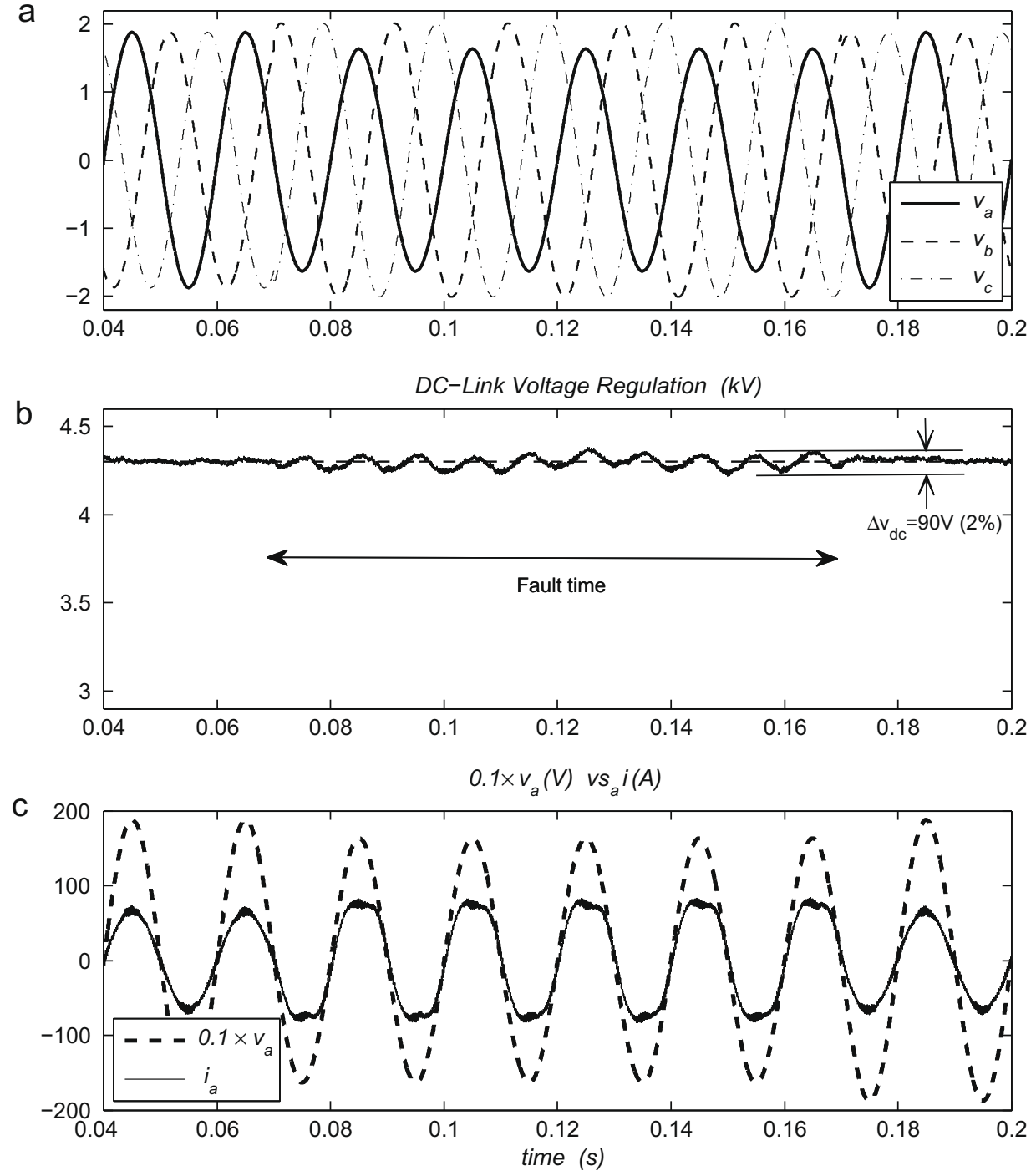

Fig. 8. Behavior under an unbalanced AC-supply.

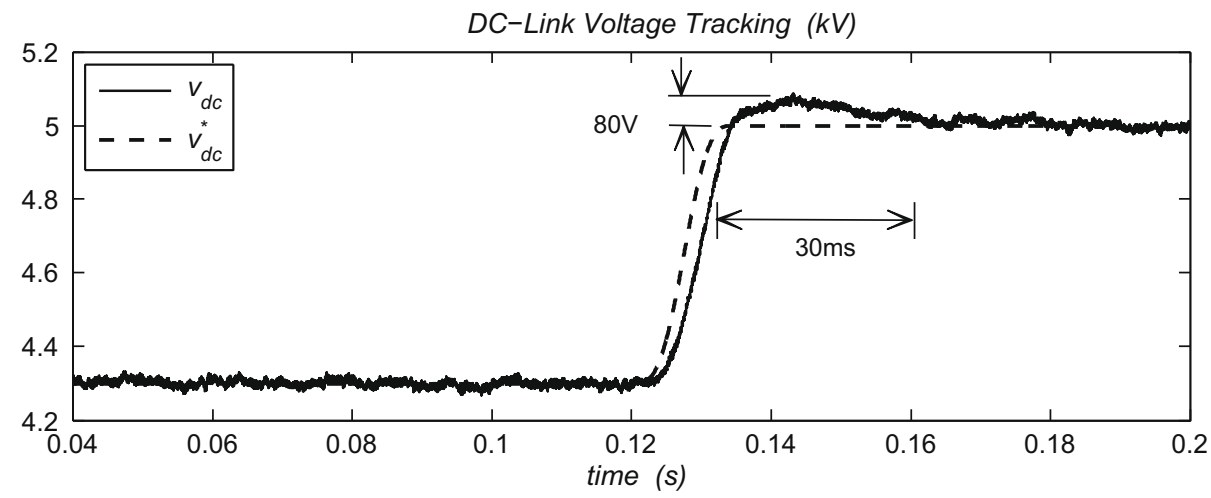

Fig. 9. DC-link voltage tracking.

illustrates the transient and steady state behavior. Note that the proposed strategy performs very well.

\section{Conclusions}

In this paper a new control strategy for VSCs is introduced. The proposed controller combines a feedback law based on feedback linearization with a feedforward compensation from estimated load current. The main advantages are: outputs are chosen such that complete feedback linearization, without model simplifications and avoiding internal dynamics, is obtained. In this way, linear control laws can be used to control two decoupled subsystems avoiding the slow response caused by the DC-voltage cascade control. Also, unity power factor, high-performance DC-voltage con- 
trol, and bidirectional power flow are attained. In addition, feedforward compensation allows to improve the performance, when the capacitor size is considerably reduced. The discretized control law is robust against parameters uncertainties, measurement filters delays, high frequencies due to PWM techniques and input AC voltage disturbances.

\section{Acknowledgement}

A.E. León thanks J.M. Mauricio (Universidad de Sevilla) for useful discussions maintained during the develop of this work.

\section{References}

[1] Yazdanpanah R, Soltani J, Arab Markadeh GR. Nonlinear torque and stator flux controller for induction motor drive based on adaptive input-output feedback linearization and sliding mode control. Energy Convers Manage 2008;49(4):541-50.

[2] Chuang T-S, Liang J-W. A stator flux oriented current vector control of a sensorless 6/4 SRM for reduction of acoustic noise and vibration. Energy Convers Manage 2008. doi:10.1016/j.enconman.2008.06.003.

[3] Calleja H, Jimenez H. Performance of a grid connected PV system used as active filter. Energy Convers Manage 2004;45(15-16):2417-28.

[4] Ghosh A, Ledwich G. A unified power quality conditioner (UPQC) for simultaneous voltage and current compensation. Electr Power Syst Res 2001;59(1):55-63.

[5] Fujita $H$. Akagi $H$. The unified power quality conditioner: the integration of series and shunt-active filters. IEEE Trans Power Electron 1998;13(2):315-22.

[6] Molina MG, Mercado PE, Watanabe EH. Static synchronous compensator with superconducting magnetic energy storage for high power utility applications. Energy Convers Manage 2007;48(8):2316-31.

[7] Ngamroo I, Taeratanachai C, Dechanupaprittha S, Mitani Y. Enhancement of load frequency stabilization effect of superconducting magnetic energy storage by static synchronous series compensator based on $\mathrm{H}_{\infty}$ control. Energy Convers Manage 2007;48(4):1302-12.

[8] Asplund G, Eriksson K, Svensson K. HVDC light DC transmission based on voltage sourced converters. ABB Rev 1998;1:4-9.

[9] Carrasco JM, Franquelo LG, Bialasiewicz JT, Galvan E, Guisado RCP, Prats MAM, et al. Power-electronic systems for the grid integration of renewable energy sources: a survey. IEEE Trans Ind Electron 2006;53(4):1002-16.

[10] Camblong H, Martinez de Alegria I, Rodriguez M, Abad G. Experimental evaluation of wind turbines maximum power point tracking controllers. Energy Convers Manage 2006;47(18-19):2846-58.

[11] Vechiu I, Camblong H, Tapia G, Dakyo B, Curea O. Control of four leg inverter for hybrid power system applications with unbalanced load. Energy Convers Manage 2007;48(7):2119-28

[12] Dufo-López R, Bernal-Agustín JL. Influence of mathematical models in design of PV-Diesel systems. Energy Convers Manage 2008:49(4):820-31.

[13] Jenkins DP, Fletcher J, Kane D. Model for evaluating impact of battery storage on microgeneration systems in dwellings. Energy Convers Manage 2008;49(8):2413-24

[14] Idjdarene K, Rekioua D, Rekioua T, Tounzi A. Vector control of autonomous induction generator taking saturation effect into account. Energy Convers Manage 2008. doi:10.1016/j.enconman.2008.05.014.

[15] Bansal RC. Modelling and automatic reactive power control of isolated winddiesel hybrid power systems using ANN. Energy Convers Manage 2008;49(2):357-64.
[16] Blasco V, Kaura V. A new mathematical model and control of a three-phase AC-DC voltage source converter. IEEE Trans Power Electron $1997 ; 12(1): 116-23$.

[17] Tsai M-T, Tsai WI. Analysis and design of three-phase AC-to-DC converters with high power factor and near-optimum feedforward. IEEE Trans Ind Electron 1999;46(3):535-43.

[18] Cecati C, Dell'Aquila A, Lecci A, Liserre M. Implementation issues of a fuzzylogic-based three-phase active rectifier employing only voltage sensors. IEEE Trans Ind Electron 2005;52(2):378-85.

[19] Allag A, Hammoudi M, Mimoune SM, Ayad MY, Becherif M, Miraoui A. Tracking control via adaptive backstepping approach for a three phase PWM AC-DC converter. In: IEEE international symposium on industrial electronics, ISIE'07; 2007. p. 371-6.

[20] Escobar G, Chevreau D, Ortega R, Mendes E. An adaptive passivity-based controller for a unity power factor rectifier. IEEE Trans Control Syst Technol 2001;9(4):637-44.

[21] Mendalek N, Al-Haddad K, Fnaiech F, Dessaint LA. Nonlinear control technique to enhance dynamic performance of a shunt active power filter. IEE Proc Electr Power Appl 2003;150(4):373-9.

[22] Lee T-S. Input-output linearization and zero-dynamics control of three-phase AC/DC voltage-source converters. IEEE Trans Power Electron 2003;18(1):11-22.

[23] Ayad M-Y, Pierfederici S, Rael S, Davat B. Voltage regulated hybrid DC power source using supercapacitors as energy storage device. Energy Convers Manage 2007;48(7):2196-202.

[24] Lee T-S, Tzeng K-S. Input-output linearizing control with load estimator for three-phase AC/DC voltage-source converters. In: IEEE 33rd power electronics specialists conference, PESC'02, vol. 2(4); 2002. p. 791-5.

[25] Nikkhajoei H, Iravani R. Dynamic model and control of AC/DC/AC voltagesourced converter system for distributed resources. IEEE Trans Power Deliv 2007;22(2):1169-78.

[26] Burgos RP, Wiechmann EP. Extended voltage swell ride-through capability for PWM voltage-source rectifiers. IEEE Trans Ind Electron 2005;52(4):1086-98.

[27] Lee D-C, Lee G-M, Lee K-D. DC-bus voltage control of three-phase AC/DC PWM converters using feedback linearization. IEEE Trans Ind Appl 2000;36(3):826-33.

[28] Ye Y, Kazerani M, Quintana VH. Modeling, control and implementation of three-phase PWM converters. IEEE Trans Power Electron 2003;18(3):857-64.

[29] Itako K, Mori T. Unity power factor PWM rectifier reducing the number of sensors. In: European conference on power electronics and applications, EPE'05; 2005. p. 1-10.

[30] Gensior A, Rudolph J, Guldner H. Flatness based control of three-phase boost rectifiers. In: European conference on power electronics and applications, EPE'05; 2005. p. 1-9.

[31] Solsona J, Valla MI, Muravchik C. A nonlinear reduced order observer for permanent magnet synchronous motors. IEEE Trans Ind Electron 1996;43(4):492-7.

[32] Slotine J-JE, Li W. Applied nonlinear control. NJ (USA): Prentice-Hall; 1991.

[33] León AE, Solsona JA, Busada C, Chiacchiarini H, Valla MI. A novel feedback/ feedforward control strategy for three-phase voltage-source converters. In: IEEE International Symposium on Industrial Electronics, ISIE'07; 2007. p. 3391-6.

[34] Ogata K. Modern control engineering. 3rd ed. Prentice-Hall; 1997.

[35] Esfandiari F, Khalil HK. Output feedback stabilization of fully linearizable systems. Int J Control 1992;56:1007-37.

[36] Teel A, Praly L. Tools for semi-global stabilization by partial state output feedback. SIAM J Control Optimizat 1995;22:1443-88.

[37] Etchechoury M, Solsona J, Muravchik C. On the stability of nonlinear plants that include an observer for their feedback linearization. Int J Syst Sci 1996;27:1461-6.

[38] Etchechoury M, Solsona J, Muravchik C. Feedback linearization via state transformation using estimated states. Int J Syst Sci 2001;32(1):1-7. 